Available online at www.sciencescholar.us

Vol. 6 No. 1, April 2022, pages: 32-39

e-ISSN: 2550-696X, p-ISSN: 2550-6978

https://doi.org/10.53730/ijhs.v6n1.3063

\title{
Assessment of Situation in Educational Activities with Need to Introduce Remote Technologies during Pandemic
}

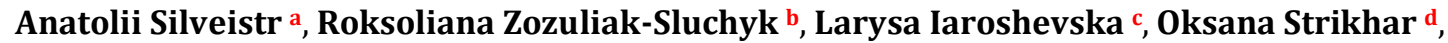 \\ Svitlana Derkach e
}

Manuscript submitted: 7 August 2021, Manuscript revised: 18 November 2021, Accepted for publication: 20 December 2021

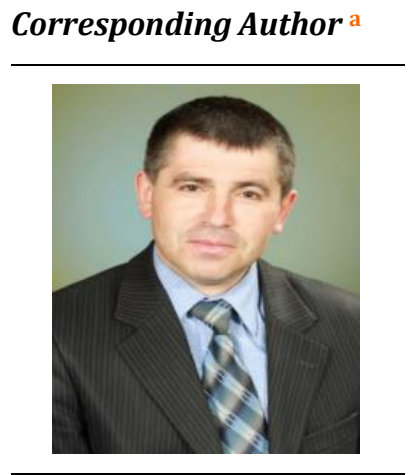

Keywords

distance education; education development; educational organization; educational process; educational technology; health opportunity; internet resource; lifelong education; pandemic;

\begin{abstract}
The article aims to assess the options for DO according to their requirements for the competencies of employees; the correspondence of the existing competencies of the personnel to work with subsidiaries was revealed; Substantiated the criteria for choosing a subsidiary, taking into account the compliance with the objectives of the organization and the revealed discrepancy of competencies; methods for calculating labor costs are proposed; the possible motivational techniques were evaluated, to use them in personnel management in the process of transition to the use of distance learning in the educational process. The article identifies and analyzes various groups of risks associated with this process (prejudices, risks of losing that value that is accumulated by pedagogical experience, risks associated with the loss and change of authority in the teaching staff), the possibilities of their leveling, directions of work with them are offered. analysis of existing preschool education, based on the needs of the teaching staff, additional criteria for the selection of preschool education have been formulated.
\end{abstract}

International Journal of Health Sciences (C) 2022. This is an open access article under the CC BY-NC-ND license (https://creativecommons.org/licenses/by-nc-nd/4.0/).

\section{Contents}

Abstract

1 Introduction

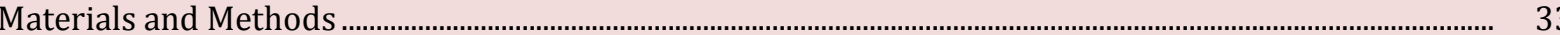

Results and Discussions

4 Conclusion

\footnotetext{
a Vinnytsia Mykhailo Kotsiubynskyi State Pedagogical University, Vinnytsia, Ukraine

b Precarpathian National University Vasyl Stefanyk, Ivano-Frankivsk, Ukraine

c Nikolaev national university named after V.O. Sukhomlinsky, Nikolaev, Ukraine

${ }^{d}$ Nikolaev national university named after V.O. Sukhomlinsky, Nikolaev, Ukraine

e Kyiv National University of Culture and Arts, Kyiv, Ukraine
} 
Acknowledgments..

\section{Introduction}

The relevance of the article is associated with the widespread use of Internet technologies in modern society, including in one of its main institutions - in education. The use of distance technologies (hereinafter referred to as DT) in the educational process makes it more mobile, flexible, and accessible (Rovai, 2003). Also, the use of DT in the educational process increases the interest of students, allows them to be more actively involved in the educational process. The teacher's use of DT in the educational process brings him closer to the modern level of technology development, serves to develop his competencies in this area, and increases his level of self-esteem (Harris \& Sutton, 1986). The use of modern technologies (including Internet resources) in the educational process makes it more open, including in life, serves, in the end, result, as a tool for improving the quality of the educational process, providing the ability to flexibly respond to the needs of society, to track the results in a mobile way (Mayo et al., 2003; Khalil et al., 2020). learning. In addition, the introduction of DT into the educational process provides an opportunity for the development of lifelong education, gives wider prospects for inclusive learning: they make it easier and faster to form individual educational plans (routes), do not allow low-mobility, temporarily disabled students, persons with disabilities to fall out of the current educational process, health opportunities.

All these processes, necessary in the modern situation of education development, make it possible to talk about the need to introduce DT into the educational process (Ankem, 2004). However, the use of new technical, methodological, and organizational means is possible only with the active participation of the main aspects of the educational process - teachers, auxiliary personnel, students - which cannot be achieved without special efforts, since all these parties have their own established interests, habits and relationships that are violated by the introduction of diesel fuel (like any innovation). The creation of favorable conditions for the transition of participants in the educational process to work in new conditions is becoming an indispensable condition for achieving these results - the use of diesel fuel in the educational process. The master's thesis has the character of a project with a research component, which is necessary for diagnosing the characteristics of a specific organization, namely, teaching staff, their potential for readiness to master new educational technologies and develop measures to develop this potential and stimulate workers in the process of mastering and using distance technologies: rationing labor costs when working with a distance learning system, the choice and - if necessary - adapting it to the needs of the educational organization (Rovai \& Downey, 2010; Kotsiantis et al., 2010). The purpose of the article, which is achieved in the course of solving problems, is to provide methodological recommendations necessary for organizing a personnel management system during the transition to the use of distance learning in the educational process (Iasechko et al., 2021).

\section{Materials and Methods}

The issue of using distance technologies (hereinafter referred to as DT) in the educational process is solved by each educational organization (hereinafter referred to as EO) in its way: from the use of elements of DT to the introduction of a distance learning system (hereinafter referred to as EO) into the EO. To complete the picture of the use of diesel fuel in the educational process, it is necessary to note the use of the so-called. Cloud technologies. At the moment, they cannot fully meet all the needs of vocational education organizations, because have some disadvantages, namely: the lack of an integrated system for managing the educational process, the formation of individual educational trajectories, ensuring the protection of students' data, due to the specifics of the placement of servers serving this technology, the inability to form test options by randomly selecting tasks, etc. Along with this, we can note the undoubted positive aspects of "cloud" technologies: the ability to read posted documents without installing special office applications, from any mobile device; ease of use; availability. The presented master's thesis will not analyze the possibilities of "cloud" technologies, but it is necessary to note their existence, advantages and the possibilities of using them as additional technologies

Silveistr, A., Zozuliak-Sluchyk, R., Iaroshevska, L., Strikhar, O., \& Derkach, S. (2022). Assessment of situation in educational activities with need to introduce remote technologies during pandemic. International Journal of Health 
for a more complete presentation of the problem. If you describe the process of introducing diesel fuel into the educational process, you need to focus on a review of the currently available options for their use (Granell et al., 2016; Cecil et al., 2018). Based on a preliminary survey of representatives of the E0, the process of introducing DT into the educational process can be divided into a step-by-step and holistic one. Employees involved in organizing training using DT in the educational process were interviewed: heads of distance learning services, additional education, organizers of distance learning in an educational organization (methodologists, tutors, etc.).

Let's consider both of these methods from the point of view of the attitude of perception and acceptance by staff. The first method consists of the phased introduction of distance learning elements: starting with the most convenient in use and application and moving on to more complex and advanced ones. A survey in the form of a conversation with representatives of various SWs shows that most often (in $74 \%$ of cases) the use of diesel fuel begins with posting educational and teaching materials (tasks, necessary methodological instructions, questions for intermediate control, etc.), and, already a little later - the development and placement of test tasks on the same resources - with the possibility of their online or off-line use (Tacconi, 1998; Widana et al., 2021). In this case, the organization is free to use its resources of the information technology department, use ready-made free (shareware) shells, or purchase subsidiaries. The main groups of distance learning platforms need to be defined immediately. At the moment there are the following types of software in this area.

Free shells - software that is freely distributed and available for free official download and installation on the websites of development companies (for example, MOODLE, Sakai, OLAT, etc.) - open-source software. Shareware shells - software that is freely distributed and available for free download and installation on the websites of developer companies only in a basic version, when using which part of the functionality is not available for use. To get a full-fledged system, payment is required (for example, Ope№Elms, Dokeos, etc.). Commercial skins - software installed (provided for use on a leasehold basis) by a development company on a commercial basis. Modifications for a specific organization are possible for an additional fee - closed-source software (Asman et al., 2021; Herliah et al.,2022).

As a rule (almost 90\%) - EOs start using and introducing DT into the educational process with free (shareware) shells, the most common of which is the MOODLE system, a platform offered by Australian developers to implement various functionality. The advantages of such a choice of the administration (namely, the DT administration makes decisions in this matter) are obvious: this is the ability to start using diesel fuel at the lowest cost, there is no need to install additional equipment, software, and the shell is available. Along with the obvious advantages, there are also negative consequences of such a decision: inevitably, the administration (as a controlling body) will need to account for various reasons - i.e. - various forms of reporting, often absent in free shells. Free (shareware) shells enable EO programmers to modify it, but, as a rule, overloading with functions that are not previously included in the shell leads to its incorrect operation, overload, and crashes. Thus, the obvious disadvantages of using free (shareware) shells (even with the possibility of their revision by the EO IT departments) include the lack of functions and incorrect operation of the revision field (weighting the system). The main disadvantage of free (conditionally free) shells is that with the development of distance learning, the expansion of the use of DT in the educational process - they cease to meet the requirements and requests of everyone involved in the educational process: students, teachers, the administration of the DT. It is noted (according to the results of surveys conducted by the master's student) the impossibility of creating interactive courses (37\%), small opportunities for the testing unit, namely, the inability to use graphics, various types of questions, random selection of tasks for each student individually (66\%), incorrect work outside the walls educational organization (89\%), weak control and identification of educational and methodological materials and limited forms of statistical reporting (39\%) and system overload - all this leads to the need to develop its own shell (if there are strong programmers in the E0) or to purchase a full-fledged DT from developers ... In this case, the transitions from one system to another are negatively perceived by the teaching staff: a persistent feeling of unnecessary actions is created ("they tried, posted materials, everything was gone; do everything again"), there is a reluctance to retrain and work in another system ("they will change it anyway"). Similar reactions occur in $79 \%$ of the respondents, even though the staff does not deny the convenience of using DT in the educational process, assesses the advantages: the transfer of materials to students, the possibility of testing. Let us consider the situation in which a part of educational institutions of vocational education finds itself realizing 
the impossibility of rejecting distance learning in the modern situation. Today, educational organizations use, to one degree or another, elements of distance learning. As noted above, most often this is either a free (shareware shell) - according to the analysis of EO sites - most often it is MOODLE (about 90\% EO) - or our developments (no more than $4 \%$ E0). In only $6 \%$ of cases, the SW administration immediately decides to purchase a commercial platform (Tolmacheva et al., 2021; Ernawati et al., 2022).

When choosing MOODLE and its development, two functions are realized: storage of text files and a testing system. If the testing system makes it possible to test knowledge (skills and practical skills remain "untouched"), then the maximum that the repository of text documents gives us is an electronic form of the abstract of the educational (teaching and methodological) manual, which makes it possible to use it as a printed analog. There is no need to talk about interactivity, attracting attention, etc., as well as simple (inactions) actualization. All these data lead to the need to change the existing situation (Clase et al., 2020). But to make the work on the implementation of diesel fuel most effective, it is necessary to correlate solutions with real needs, i.e. - be based on the received factual material. It was to obtain the necessary factual material that many surveys were conducted. The survey was carried out several times - initially - to clarify the perceived need for the use of diesel fuel; then - to find out the satisfaction with the existing ones; the latter is to identify additional needs, fears, risks, benefits, and preferences that have arisen. The initial survey was conducted after the abandonment of MOODLE and before any development. The survey involved 95 teachers ( $82 \%$ of the total number of EO full-time teachers). The survey showed that the proposed at this stage of use in the EO DT were used in the educational process by $67 \%$ of the respondents.

Out of this number of teachers: $34 \%$ (which amounted to $22.8 \%$ of the total number of respondents) selected and posted their materials in the system themselves (for the rest it was done by methodologists or secretaries, as a rule, under their account), $17 \%$ (11, 4\% of the total number of respondents) - recommended them for use by students. At the same time, as additional wishes, there was a lack of opportunities to control knowledge in automatic mode (19\%, or $12.7 \%$ of the total number of respondents) and the absence of various statistics $(23 \%$, or $15.4 \%$ of the total number of respondents). The shares obtained are necessary to form a holistic picture of attitudes towards the introduction of new technologies into the educational process: thus, we have at our disposal data concerning both the entire teaching staff as a whole and relations within the group who used DT in their practice. Thus, the EO has come to the stage at which it is necessary to think about acquiring an integral SO (taking into account experience and the impossibility for the EO's IT structures to develop an independent system - and the senselessness of this work, as too costly and time-consuming subject to the availability of professional developers, completely specializing in DO).

The analysis of the submitted questionnaires gives us an augmented nature of preferences and prejudices, which is explained by a wide range of EO specialties, based on which this study was conducted. This gives reason to believe that the data obtained can be indicative for EOs of various directions (averaged character), but in each specific case, they need a more detailed study of the relationship at the subsequent stages of introducing DT into the educational process - for example, when distributing roles in working with a distance learning system. learning. In an SW with a clearer technical specialization, there will likely be no fears associated with the lack of personal competence of teachers in the field of IT. But it cannot be ruled out that in the federal state educational standards of secondary vocational education, in the formation of the training program for middle-level specialists, in addition to the professional educational cycle, disciplines of the general humanitarian and socio-economic educational cycles are implemented, which implies the presence in the pedagogical collective of teachers of these cycles, which will also have to to be involved in the process of using DT in the educational process, therefore, will bring "humanitarian" fears and prejudices to the total number. In this regard, at this stage - the stage of selection of distance learning platforms - sufficient (and typical) may be the results of a general survey without breaking down into the profiles of the disciplines taught. Further systematization of the data obtained makes it possible to identify preferences in working with DL, depending on the orientation of the taught, to combine them into groups and outline future roles in working with DL and identify motivational moments.

Data analysis provides a clear division of future roles: developers and processors of materials can be attracted from teachers of technical and natural sciences who have shown the greatest (among the respondents) aptitude for this type of work. Processors and those responsible for collecting statistics should be chosen from among teachers of socio-economic disciplines; curators of groups of students - from teachers of humanitarian and socio-economic disciplines; tutors and methodologists of DL - from representatives of

Silveistr, A., Zozuliak-Sluchyk, R., Iaroshevska, L., Strikhar, O., \& Derkach, S. (2022). Assessment of situation in educational activities with need to introduce remote technologies during pandemic. International Journal of Health Sciences, 6(1), 32-39. https://doi.org/10.53730/ijhs.v6n1.3063 
humanitarian and natural science orientation taught. This division into groups connecting the preferences and orientation of the teachers allows us to talk about the motivational component, which can be used in working with representatives of each of the groups: to involve in the learning process; offer ben efits from materials development; material incentives for such employees. Analysis of the survey results revealed many concerns and biases that can be generalized and grouped. The first group of concerns is associated with concerns that reflect the competence of the teacher: lack of work skills, work complexity, etc. In this case, many measures are envisaged.

- Related to the peculiarities of the chosen platform - the friendliness of the interface, adaptation of the template product to the needs of the EO;

- Related to personnel training - the constant conduct of both planned courses on working with the system and individual consultations.

Most of such fears are removed at the stage of choosing the DL platform, taking into account the criteria that are formed additional to the basic versions: this is the system interface, and the possibility of training, including in the development company, and the possibility of transferring (importing) already available data. Regular training is also associated with measures to overcome this group of fears and prejudices: by the educational and methodological services of the EO and/or with the involvement of specialized structures (for example, a developer company). The second group of fears is associated with being obligated, unwilling to, rejecting, and not seeing one's role in work in preschool education. The survey data show that almost a fifth would prefer not to work in the system. In this case, it is necessary (before the introduction of DT - like any innovation) interest in this process of the SW leadership to promote the ideas of DT in the EO, to organize and support a system of incentives for workers in preschool education, define roles for work in preschool education and build a system of work on the implementation of DT generally. Also, the data gives an idea of the presence of a group of "innovators" - those who want to not only work but also train others, not only transfer materials but also independently develop their own using the tools offered by the system. The survey also showed a predictable division of roles: a tutor or curator (working with a group), a tutor (working with fellow teachers), a developer (creating or processing content), a moderator (collecting and analyzing statistics), and an administrator (supervising the entire process or part of it, depending on the scale of coverage). Thus, measures aimed at overcoming this group of risks will include:

- Development of a system for the implementation of diesel fuel in the EO - a schedule, a set of measures, including incentives for employees working in subsidiaries;

- The obligatory clear division of the main roles (including the identification of those who want to train others and their sending for training to the development company) and the building of training programs and training schedule on the spot - by the forces of employees trained in the development company. To do this, it is necessary to conduct an additional survey - in this case - in the form of a personal conversation, targeted to identify individual employees who want to work in one or another aspect of using the DOs.

- The gradual inclusion of the largest number of teachers and students in the process of using DT, as well as other units of the EO - a demonstration of the advantages and capabilities of DL. The survey shows a change in attitudes towards DT as a whole, an awareness of the benefits that they give to participants in the educational process, the presence of a desire to work with new technologies, subject to their involvement in the educational process, avoiding formalization (Iasechko et al., 2021).

- Constant use of data provided by DOs in work - to form a positive image of the system itself and attitude towards it. Engaging not only pedagogical staff and students but also administrative and personnel workers, employees of development and vocational guidance centers, teaching and educational services to work in preschool education. The third group of concerns reflects concerns related to the appropriation of content plagiarism. In this case, the means of protecting authorship and copyright can be the registration of electronic educational resources with the receipt of a certificate of state registration confirming the copyright. A technical means of overcoming these concerns is the identification of users and the recording of all possible actions performed in the DO (name registration in the system, authorization, synchronization with AD). If there is a module for collecting statistical data in the system, the DL administrator can view the history of visits as students at any time. The fourth group of concerns reflects the "history" of working with diesel fuel and is associated with a technical component, such as: the inability to work from any mobile devices, incorrect operation of the system, etc. These fears are removed at the stage of technical selection of 
the system - in the given selection criteria, wishes for a potential system, all of them are indicated. Also, it should be noted that most modern DOs provide these capabilities in the basic version.

\section{Results and Discussions}

The most difficult is the fifth group of fears associated with the psychology of attitudes towards education, with a historical component: a private change of shells, addiction, lack of demand for materials, etc. The installation of a holistic DO, corresponding to the maximum set of EO requirements, working correctly, promising in terms of capabilities, and set for a sufficiently long time, will remove negative aspects about DO. Once again, initial and constant support from the EO administration is needed, which allows forming a positive image of DL in the educational process, as mentioned above. Generalized measures to remove fears and prejudices must be implemented step by step, starting with teaching the basics of working with diesel fuel, disseminating this experience within the EO, showing the benefits of using diesel fuel in the educational process (mobility, saving time, automating the verification process, collecting statistical data), planning use DT in EO outside the framework of the implementation of basic educational programs (training, additional programs focused on third-party clients, etc.). For a step-by-step introduction and involvement in the use of DT in the educational process, it is necessary to rely on a group of "innovators" (Iasechkoet al., 2021), who will form the basis for working groups, groups of tutors for preschool education, methodologists-administrators of preschool education and serve as guides for innovations in EO in general.

The advantages of this category should be reflected in the further change in their status in the SW (the emergence of new positions, an increase in status), associated with these wages. The aforementioned timesaving in the automation of individual processes of extracurricular educational and methodological work can also serve as an advantage for a group of "innovators" who use DT and disseminate their experience in the teaching staff and as a motivator for introducing DT into the educational process. After analyzing the empirical material, identifying and classifying fears, and suggesting possible ways to remove these fears and prejudices, as well as analyzing existing distance learning platforms, it is necessary to move on to practical recommendations for further work on the implementation of DT in the educational process. These include a standard plan for the implementation of diesel fuel in the educational process, standard local regulations, methods for calculating wages, other methods of motivation, etc. The fourth chapter of the master's thesis is devoted to this practical aspect. Speaking about any process of introducing something new into any workflow, it is noted that it is advisable to start any implementation process with the formation and approval of a work schedule. This applies to any innovations (for example, quality management systems, etc.). It also confirms the opinion of researchers in the field of innovation and personnel management about the need for consistency of all actions: "Alignment: the alignment between strategy and the four main building blocks of the organization: core tasks and workflows, formal organizational structures, staff, and culture. Inconsistency, inconsistency, and inconsistency of these elements is the reason for the efficiency gaps" (POLAT, 2021).

\section{Conclusion}

Thus, the assessment of DO options was carried out according to their compliance with the tasks of the organization and according to their requirements for the competencies of employees; revealed, using a questionnaire, the results of which are described in the article, the conformity, and inconsistency of the existing competencies of personnel with work with subsidiaries; Criteria for choosing a subsidiary have been substantiated, taking into account the compliance with the objectives of the organization and the revealed discrepancy of competencies.

Acknowledgments

We are grateful to two anonymous reviewers for their valuable comments on the earlier version of this paper.

Silveistr, A., Zozuliak-Sluchyk, R., Iaroshevska, L., Strikhar, O., \& Derkach, S. (2022). Assessment of situation in educational activities with need to introduce remote technologies during pandemic. International Journal of Health Sciences, 6(1), 32-39. https://doi.org/10.53730/ijhs.v6n1.3063 


\section{References}

Ankem, K. (2004). Adoption of Internet resource-based value-added processes by faculty in LIS $\begin{array}{llll}\text { education. Library } \quad \& \quad \text { information } & \text { science } & \text { research, 26(4), }\end{array}$ https://doi.org/10.1016/j.lisr.2004.04.008

Asman, A., Asman, A., \& Dewi, A. K. (2021). Community nursing strategies for tourism health families during COVID-19 pandemic. International Journal of Health Sciences, 5(3), 224-231. https://doi.org/10.53730/ijhs.v5n3.1449

Cecil, J., Gupta, A., Pirela-Cruz, M., \& Ramanathan, P. (2018). An IoMT based cyber training framework for orthopedic surgery using Next Generation Internet technologies. Informatics in Medicine Unlocked, 12, 128137. https://doi.org/10.1016/j.imu.2018.05.002

Clase, C. M., Fu, E. L., Ashur, A., Beale, R. C., Clase, I. A., Dolovich, M. B., ... \& Carrero, J. J. (2020, July). Forgotten technology in the COVID-19 pandemic. Filtration properties of cloth and cloth masks: a narrative review. In Mayo Clinic Proceedings. Elsevier. https://doi.org/10.1016/j.mayocp.2020.07.020

Ernawati, E., Baso, Y. S., Hidayanty, H., Syarif, S., Aminuddin, A., \& Bahar, B. (2022). The effects of anemia education using web-based she smart to improve knowledge, attitudes, and practice in adolescent girls. International Journal of Health \& Medical Sciences, 5(1), 44-49.

Granell, C., Havlik, D., Schade, S., Sabeur, Z., Delaney, C., Pielorz, J., ... \& Mon, J. L. (2016). Future Internet technologies for environmental applications. Environmental Modelling \& Software, 78, 1-15. https://doi.org/10.1016/j.envsoft.2015.12.015

Harris, S. G., \& Sutton, R. I. (1986). Functions of parting ceremonies in dying organizations. Academy of Management journal, 29(1), 5-30.

Herliah, A., Baso, Y. S., Hidayanty, H., Syarif, S., Aminuddin, A., \& Bahar, B. (2022). Effect of web-based she smart education models on adolescent girl's knowledge, attitudes, and practice about obesity. International Journal of Health \& Medical Sciences, 5(1), 50-55.

Iasechko, M., Iasechko, S., \& Smyrnova, I. (2021). Pedagogical aspects of self-development of distance learning students in Ukraine. Laplage em Revista, 7(Extra-B), 316-323.

Iasechko, M., Kharlamov, M., Gontarenko, L., Skrypchuk, H., Fadyeyeva, K., \& Sviatnaia, O. (2021). Artificial intelligence as a technology of the future at the present stage of development of society.

Iasechko, M., Shelukhin, O., Maranov, A., Lukianenko, S., Basarab, O., \& Hutchenko, O. (2021). Evaluation of The Use of Inertial Navigation Systems to Improve The Accuracy of Object Navigation. International Journal of Computer Science \& Network Security, 21(3), 71-75.

Khalil, K., Elgazzar, K., Seliem, M., \& Bayoumi, M. (2020). Resource discovery techniques in the internet of things: a review. Internet of Things, 100293. https://doi.org/10.1016/j.iot.2020.100293

Kotsiantis, S., Patriarcheas, K., \& Xenos, M. (2010). A combinational incremental ensemble of classifiers as a technique for predicting students' performance in distance education. Knowledge-Based Systems, 23(6), 529-535. https://doi.org/10.1016/j.knosys.2010.03.010

Mayo, G. L., Lindhorst, G. C., \& Rosende, C. (2003). American ophthalmology graduate medical education and the web: current state of internet resource utilization. American journal of ophthalmology, 135(5), 708-709. https://doi.org/10.1016/S0002-9394(02)02089-5

POLAT, E.S. (2001). Distance learning models.

Rovai, A. P. (2003). In search of higher persistence rates in distance education online programs. The internet and higher education, 6(1), 1-16. https://doi.org/10.1016/S1096-7516(02)00158-6

Rovai, A. P., \& Downey, J. R. (2010). Why some distance education programs fail while others succeed in a global environment. The Internet and Higher Education, 13(3), 141-147. https://doi.org/10.1016/j.iheduc.2009.07.001

Tacconi, L. (1998). Scientific methodology for ecological economics. Ecological Economics, 27(1), 91-105. https://doi.org/10.1016/S0921-8009(97)00134-1

Tolmacheva, S., Tkachev, A., \& Shamshin, M. (2021). The impact of the pandemic on moral panics in society. International Journal of Health Sciences, 5(3), 232-243. https://doi.org/10.53730/ijhs.v5n3.1485

Widana, I.K., Sumetri, N.W., Sutapa, I.K., Suryasa, W. (2021). Anthropometric measures for better cardiovascular and musculoskeletal health. Computer Applications in Engineering Education, 29(3), 550561. https://doi.org/10.1002/cae.22202 


\section{Biography of Authors}

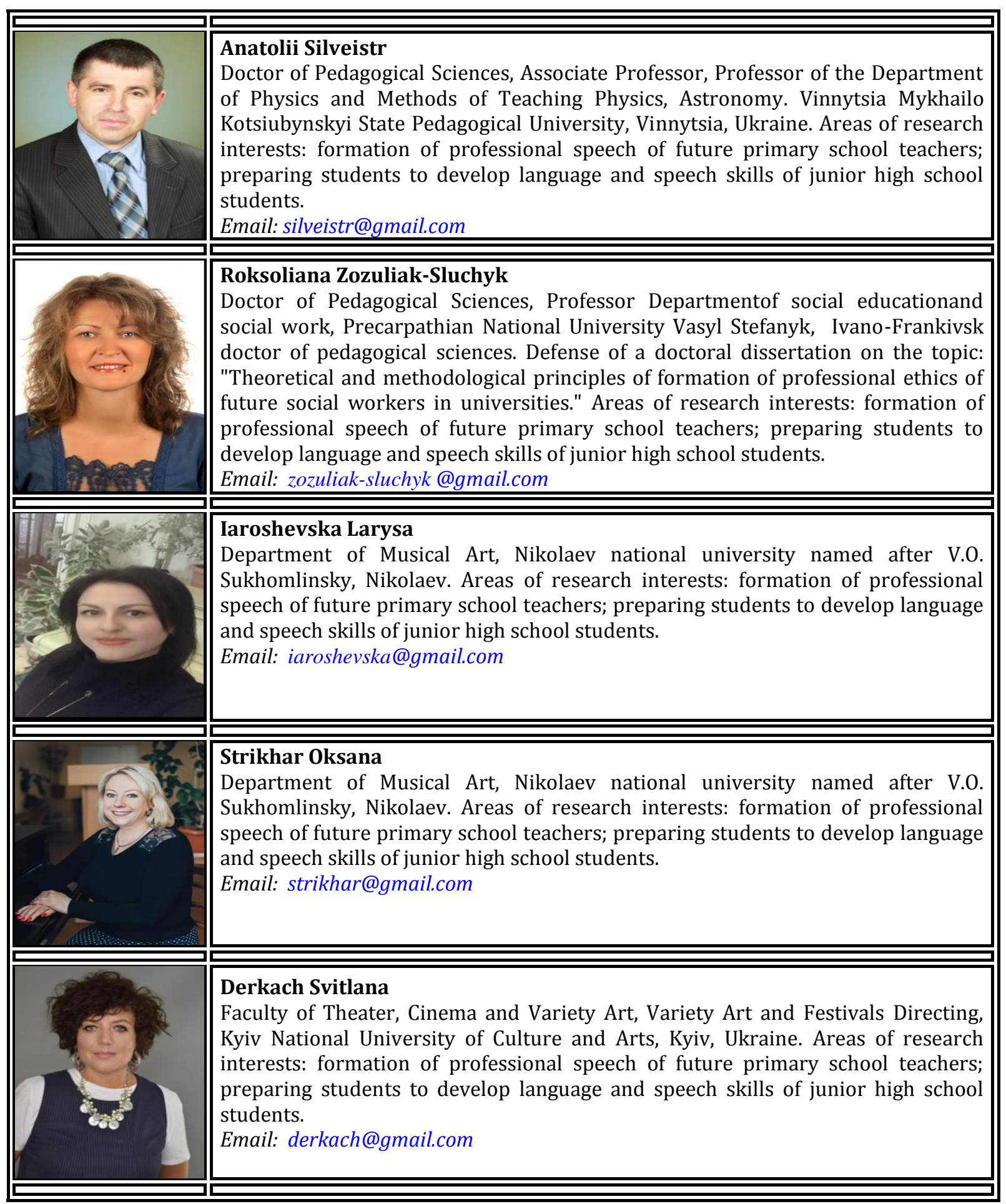

Silveistr, A., Zozuliak-Sluchyk, R., Iaroshevska, L., Strikhar, O., \& Derkach, S. (2022). Assessment of situation in educational activities with need to introduce remote technologies during pandemic. International Journal of Health Sciences, 6(1), 32-39. https://doi.org/10.53730/ijhs.v6n1.3063 